\title{
Myocardial injury in stress echocardiography: comparison of dobutamine, dipyridamole and dynamic stressors - single center study
}

\author{
Karel Medilek ${ }^{1}$, Lenka Zaloudkova ${ }^{1}$, Alexander Borg ${ }^{2}$, Lucie Brozova $^{3}$, and Josef Stasek ${ }^{1}$ \\ ${ }^{1}$ Fakultni Nemocnice Hradec Kralove \\ ${ }^{2}$ University of Malta \\ ${ }^{3}$ Masarykova univerzita Lekarska fakulta
}

March 7, 2022

\begin{abstract}
Objectives In stress echocardiography (SE), dipyridamole (DIP) and dynamic stress (ExSE) are reported as safer than dobutamine stress (DSE). We investigated whether commonly used stressors cause myocardial injury, measured by high sensitivity troponin T (hsTnT). Methods 135 patients (DSE n=46, ExsE n=46, DIP n=43) with negative SE were studied. Exclusion criteria were known ischemic heart disease (IHD), baseline wall motion abnormalities, left ventricle systolic dysfunction/regional wall motion abnormalities, septum/posterior wall [?]13 mm, diabetes, baseline hsTnT level [?]14 ng/L, baseline blood pressure [?]160/100 $\mathrm{mmHg}$, peak pulmonary pressure [?]45mmHg, eGFR $<1 \mathrm{~mL} / \mathrm{s} / 1.73 \mathrm{~m} 2$, more than mild to moderate valvular disease and dobutamine side effects. HsTnT was measured before and 180 minutes after the test. Results All patients had low pre-test probability of IHD. HsTnT increased in DSE, less so in ExSE, and unchanged in DIP group [9.4 (1.5-58.6), 1.1 (-0.9-15.7), $-0.1(-1.4-2.1) \mathrm{ng} / \mathrm{L}, \mathrm{p}<0.001]$. In DSE, hsTnT change was associated with peak dobutamine dose $(\mathrm{r}=0.30, \mathrm{p}=0.045)$, test length $(\mathrm{r}=0.43, \mathrm{p}=0.003)$ and atropine use $(\mathrm{p}<0001)$. In ExSE, hsTnT rise was more likely in females $(\mathrm{p}=0.012)$ and elderly ( $>65$ years $)(\mathrm{r}=0.32, \mathrm{p}=0.03)$, no association was found between atropine use $(\mathrm{p}=0.786)$ or test length and hsTnT rise $(\mathrm{r}=0.10$, $\mathrm{p}=0.530$ ). Conclusions DSE is associated with myocardial injury in patients with negative SE, no injury was observed in DIP and only mild one in ExSE. Whether myocardial injury is causative of the higher reported adverse event rates in DSE remains to be determined.
\end{abstract}

\section{Hosted file}

Manuscript in full 2022_2.docx available at https://authorea.com/users/464000/articles/ 559000-myocardial-injury-in-stress-echocardiography-comparison-of-dobutaminedipyridamole-and-dynamic-stressors-single-center-study

\section{Hosted file}

Figures power_point.pptx available at https://authorea.com/users/464000/articles/559000myocardial-injury-in-stress-echocardiography-comparison-of-dobutamine-dipyridamole-anddynamic-stressors-single-center-study

\section{Hosted file}

Tables . docx available at https : //authorea.com/users/464000/articles/559000-myocardial-injuryin-stress-echocardiography-comparison-of-dobutamine-dipyridamole-and-dynamic-stressorssingle-center-study 